\title{
Língua villosa nigra
}

\author{
Black hairy tongue
}

Palavras-chave: Língua villosa nigra; Leucoplasia oral;

Keywords: Lingua villosa nigra; Black hairy tongue

Apresentamos o caso de uma mulher de 88 anos, grau 5 na escala de Rankin modificada, com antecedentes pessoais de demência vascular. Cronicamente medicada com quetiapina, trazodona, lorazepam e ciamemazina. Apresenta-se no Serviço de Urgência por clínica compatível com infecção do trato urinário. Ao exame objectivo, constatada alteração da coloração do dorso da língua e a presença de papilas filiformes de coloração negra e acastanhada predominantemente na região pré-sulcal (Figura 1). Trata-se de um caso de Língua villosa nigra, também conhecida como Língua pilosa negra, uma entidade clínica benigna, com prevalência estimada entre os 0,6 e 11,3\%. 0 diagnóstico é essencialmente clínico, através do exame da cavidade oral e história clínica detalhada. É frequentemente assintomática, mas pode acompanhar-se de disgeusia, náuseas e halitose e provoca habitualmente preocupações estéticas. ${ }^{1}$ A etiologia não está ainda totalmente esclarecida mas será seguramente multifactorial, sendo conhecida a sua associação com o uso de psicotrópicos, antibióticos, tabaco e álcool, assim como desidratação e maus cuidados de higiene oral. ${ }^{2,3}$ Do ponto de vista patofisiológico observa-se hipertrofia reactiva e alteração da descamação das papilas do dorso da língua, com consequente acumulação de resíduos e microorganismos. 0 tratamento consiste na correção dos desencandeantes identificados, na optimização da higiene oral e na promoção da descamação da língua através de métodos físicos, como a escovagem, sendo também possível a utilização de agentes químicos como retinóides ou ácido salicílico. ${ }^{2,4}$ No caso clínico apresentado, foi institituída antibioterapia empirica para tratamento da infecção do trato urinário, ajustada a medicação psicotrópica e reforçados cuidados de higiene oral. A doente evoluiu favoravelmente.

\section{Bibliografia}

1. Gurvits GE, Tan A. Black hairy tongue syndrome. World J Gastroenterol. 2014;20(31):10845-50.

2. Schlager E, St claire C, Ashack K, Khachemoune A. Black Hairy Tongue: Predisposing Factors, Diagnosis, and Treatment. Am J Clin Dermatol. 2017;18(4):563-569.

3. Jhaj R, Gour PR, Asati DP. Black hairy tongue with a fixed dose combination of olanzapine and fluoxetine. Indian J Pharmacol. 2016;48(3):318-20.

4. Korber A, Dissemond J. Images in clinical medicine. Black hairy tongue. $N$ Engl J Med. 2006;354(1):67. Diagnóstico

\section{Diagnosis: Língua villosa nigra}

Black hairy tongue

\section{Filipa Sousa, Pedro Neto}

Medicina Interna do Centro Hospitalar do Baixo Vouga

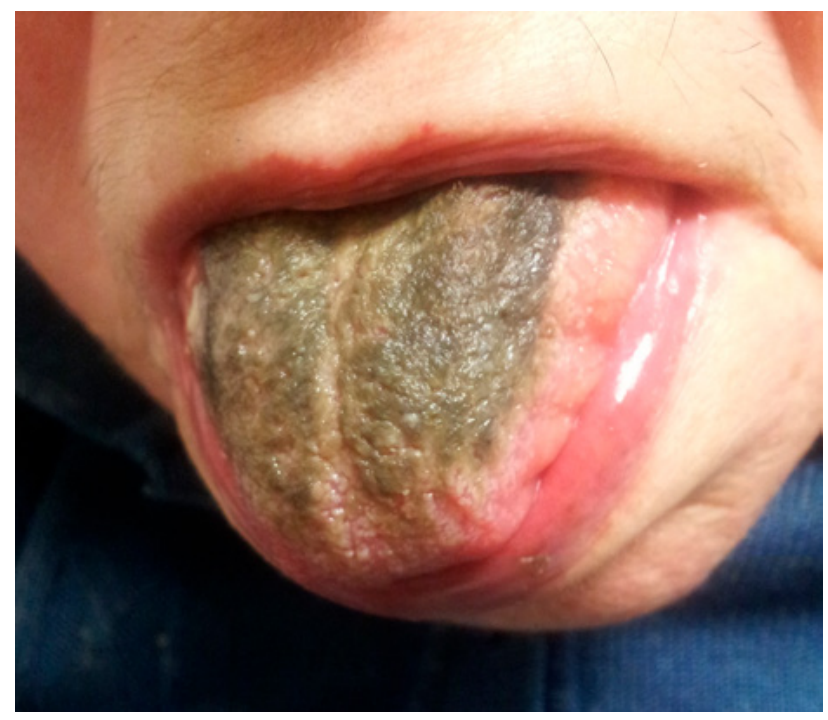

